\title{
Clinical Influence of Anastomotic Leakage on Esophageal Cancer Survival and Recurrence
}

\author{
TORU AOYAMA*, KEISUKE KAZAMA*, YOSUKE ATSUMI, HIROSHI TAMAGAWA, \\ AYAKA TAMAGAWA, KEISUKE KOMORI, DAISUKE MACHIDA, YUKIO MAEZAWA, KAZUKI KANO, \\ KENTARO HARA, MASAAKI MURAKAWA, MASAKATSU NUMATA, TAKASHI OSHIMA, \\ NORIO YUKAWA, MUNETAKA MASUDA and YASUSHI RINO
}

Department of Surgery, Yokohama City University, Yokohama, Japan

\begin{abstract}
Background: We investigated the clinical influence of anastomotic leak (AL) on esophageal cancer survival and recurrence after curative surgery. Patients and Methods: This study included 122 patients who underwent curative surgery for esophageal cancer between 2008 and 2018. The patients were classified into those with AL and those without. The risk factors for overall (OS) and recurrence-free (RFS) survival were identified. Results: AL was found in 44 out of the 122 patients (36.1\%). The respective $O S$ rates at 3 and 5 years after surgery were $43.9 \%$ and $40.2 \%$ in the AL group and $63.9 \%$ and $53.2 \%$ in the non-AL group, which were significantly different ( $p=0.0049)$. In contrast, the respective RFS rates at 3 and 5 years after surgery were $44.8 \%$ and $29.8 \%$, and $44.9 \%$ and $42.4 \%$, which were not significantly different $(p=0.2306)$. A multivariate analysis showed that $A L$ was a significant independent risk factor for both poorer OS and RFS in patients who underwent curative surgery for esophageal cancer. Conclusion: To improve survival of patients with esophageal cancer, the surgical procedure, perioperative care and surgical strategy must be carefully planned in order to prevent $A L$.
\end{abstract}

More than 450,000 new esophageal cancer diagnoses and more than 400,000 deaths per year were reported to occur worldwide in 2012. Esophageal cancer is the eighth-most common cancer in the world and the sixth-most common cause of death due to cancer (1). Complete resection is essential for curing esophageal cancer $(2,3)$, however, $20 \%$ to

*These Authors contributed equally to this study.

Correspondence to: Toru Aoyama, Department of Surgery, Yokohama City University, 3-9 Fukuura, Kanazawa-ku, Yokohama 236-0004, Japan. Tel: +81 457872800, Fax: +81 457870226, e-mail: t-aoyama@lilac.plala.or.jp

Key Words: Esophageal cancer, anastomosis leak, overall survival, recurrence.
$60 \%$ of patients who undergo esophagectomy for esophageal cancer suffer postoperative surgical complications.

Recent studies have suggested that postoperative surgical complications clinically influence a patient's survival and pattern of recurrence (4-7). Among surgical complications, anastomotic leak (AL) is one of the most clinically influential factors in survival and recurrence pattern in patients with several different malignancies (8-10). AL can lead to difficulty with oral intake, malnutrition, and a prolonged hospital stay $(11,12)$. These adverse events might lead to early recurrence or death.

Based on previous findings, we hypothesized AL to be clinically influential on survival and recurrence in patients undergoing curative resection for esophageal cancer. The present retrospective study explored whether or not overall (OS) and recurrence-free (RFS) survival were affected by the development of $\mathrm{AL}$ in patients who underwent curative resection for esophageal cancer.

\section{Patients and Methods}

Patient data. The patients were selected from the medical records of consecutive patients who underwent esophagectomy for esophageal cancer at Yokohama City University from January 2005 to September 2018. The inclusion criteria were as follows: (i) histologically proven primary esophageal squamous cell carcinoma or adenocarcinoma, (ii) clinical stage IB to III disease as evaluated using the seventh edition of the tumor-node-metastasis classification established by the Union for International Cancer Control, and (iii) complete (R0) resection of esophageal cancer with radical lymph node dissection (13). Patients who had undergone R2 or R1 resection were excluded from the study.

Surgical procedure. Our standard procedures consisted of open subtotal esophagectomy via right thoracotomy. Reconstruction used a gastric tube through the retrosternal route or posterior mediastinal route. Anastomosis was made at the cervical incision. In principle, two-field lymph node dissection was indicated when tumors were located at the lower to middle thoracic esophagus, while three-field dissection was applied for upper thoracic tumors. 
Table I. Definition of anastomotic leak as adapted from the Surgical Infection Study Group (14).

\begin{tabular}{|c|c|c|}
\hline Leak & Definition & Treatment \\
\hline Radiological & No clinical signs & No change in management \\
\hline \multirow[t]{3}{*}{ Clinical, minor } & Local inflammation cervical wound X-ray indicated leak & Drain wound \\
\hline & (thoracic anastomosis) & Delayed oral intake \\
\hline & Elevation of: fever, white blood cell count, $\mathrm{C}$ reactive protein & Antibiotics \\
\hline Clinical, major & Severe disruption on endoscopy Sepsis & $\begin{array}{l}\text { Computed tomography-guided drainage } \\
\text { (Reintervention) }\end{array}$ \\
\hline Conduit necrosis & Endoscopic confirmation & Reintervention \\
\hline
\end{tabular}

Table II. Clinicopathological data according to anastomotic leak ( $A L)$.

\begin{tabular}{|c|c|c|c|c|c|}
\hline \multirow[b]{2}{*}{ Characteristics } & & \multirow[b]{2}{*}{ All cases, $\mathrm{n}(\%)$} & \multicolumn{2}{|c|}{ Postoperative AL, n (\%) } & \multirow[b]{2}{*}{$p$-Value } \\
\hline & & & No $(n=78)$ & Yes $(n=44)$ & \\
\hline \multirow[t]{2}{*}{ Age } & $<68$ Years & $65(53.3)$ & $43(55.1)$ & $22(50.0)$ & \multirow[t]{2}{*}{0.586} \\
\hline & $\geq 68$ Years & $57(46.7)$ & $35(44.9)$ & $22(50.0)$ & \\
\hline \multirow{2}{*}{ Gender } & Male & $106(86.9)$ & $69(88.5)$ & $37(84.1)$ & \multirow[t]{2}{*}{0.492} \\
\hline & Female & $16(13.1)$ & $9(11.5)$ & $7(15.9)$ & \\
\hline \multirow[t]{2}{*}{ Site of tumor } & Upper thoracic & $36(29.5)$ & $19(24.4)$ & $17(38.6)$ & \multirow[t]{2}{*}{0.097} \\
\hline & Lower-Middle thoracic & $86(70.5)$ & $59(75.6)$ & $27(61.4)$ & \\
\hline \multirow[t]{2}{*}{ Pathological depth of invasion } & $\mathrm{T} 1$ & $43(35.2)$ & $25(32.1)$ & $18(40.9)$ & \multirow[t]{2}{*}{0.403} \\
\hline & $\mathrm{T} 2-\mathrm{T} 4$ & $79(64.8)$ & $53(67.9)$ & $26(59.1)$ & \\
\hline \multirow{2}{*}{ Pathological lymph node status } & Negative & $62(50.8)$ & $38(48.7)$ & $24(54.5)$ & \multirow[t]{2}{*}{0.536} \\
\hline & Positive & $60(49.2)$ & $40(51.3)$ & $20(45.5)$ & \\
\hline \multirow[t]{2}{*}{ Lymphovascular invasion } & Negative & $38(31.1)$ & $23(29.5)$ & $15(34.1)$ & \multirow[t]{2}{*}{0.598} \\
\hline & Positive & $84(68.9)$ & $55(70.5)$ & $29(65.9)$ & \\
\hline \multirow[t]{2}{*}{ Lymph node dissection } & Two-field & $75(61.5)$ & $55(70.5)$ & $20(45.5)$ & \multirow[t]{2}{*}{0.006} \\
\hline & Three-field & $47(38.5)$ & $23(29.5)$ & $24(54.5)$ & \\
\hline \multirow[t]{2}{*}{ Neoadjuvant chemotherapy } & Yes & $51(41.8)$ & $34(43.6)$ & $17(38.6)$ & \multirow[t]{2}{*}{0.594} \\
\hline & No & $71(58.2)$ & $44(56.4)$ & $27(61.4)$ & \\
\hline
\end{tabular}

Perioperative care. In principle, all of the patients received the same perioperative management. Antibiotics were administered $30 \mathrm{~min}$ before surgery and then again every $3 \mathrm{~h}$ during surgery, as well as on postoperative day (POD) 2 . The patients were allowed to eat rice porridge until midnight the day before the surgery. The patients remained on ventilation overnight. Enteral nutrition and ambulation were started on POD 1. Oral intake was initiated on POD 5, beginning with water and gelatinous foods. The patients began to eat solid food on POD 10, starting with rice gruel and soft food and progressing in three steps to regular food intake.

Definition of $A L$. All data were retrospectively retrieved from the patients' records. The rate of AL was determined based on the definition of leak adapted from the Surgical Infection Study Group (Table I) (14).

Follow-up. The patients were followed-up at outpatient clinics. The follow-up program of postoperative surveillance principally consisted of a physical examination; blood chemistry assessments, including squamous cell carcinoma tumor markers, every 3 months for the first year and every 6 months thereafter; and computed tomography of the neck, chest, and abdomen every 6 months.
Disease recurrence was diagnosed based on radiographic evidence of a new suspicious low-density mass in the region of the mediastinum and lymph nodes or at other distant sites.

Evaluations and statistical analyses. Recurrence-free survival (RFS) was defined as the period between surgery and the occurrence of an event, recurrence or death, whichever came first. The overall survival (OS) was defined as the period between the date of surgery and death. The data of patients who had not experienced an event were censored at the date of the final observation. The RFS and OS curves were calculated using the Kaplan-Meier method and compared by the logrank test. The Cox proportional hazards model was used for the univariate and multivariate survival analyses to identify prognosticators. An unpaired Student's $t$-test or the chi-squared method was used to compare the two groups. $p$-Values of less than 0.05 were considered to indicate statistical significance. The survival data were obtained from hospital records. The SPSS software program (v11.0J Win; SPSS, Chicago, IL, USA) was used to perform all of the statistical analyses.

Ethics. The present study was conducted in compliance with the 'ethical guidelines for clinical research'. Informed consent for using 
Table III. Univariate and multivariate Cox proportional hazards analysis of the relationship between clinicopathological factors and overall survival.

\begin{tabular}{|c|c|c|c|c|c|c|c|c|}
\hline \multirow[b]{2}{*}{ Characteristic } & & \multirow[b]{2}{*}{$\%$} & \multicolumn{3}{|c|}{ Univariate analysis } & \multicolumn{3}{|c|}{ Multivariate analysis } \\
\hline & & & HR & $95 \% \mathrm{CI}$ & $p$-Value & HR & $95 \% \mathrm{CI}$ & $p$-Value \\
\hline \multirow[t]{2}{*}{ Age } & $<68$ Years & 65 & 1.000 & & 0.121 & & & \\
\hline & $\geq 68$ Years & 57 & 1.507 & $0.898-2.529$ & & & & \\
\hline \multirow[t]{2}{*}{ Gender } & Female & 16 & 1.000 & & & 1.000 & & \\
\hline & Male & 106 & 2.153 & $0.780-5.949$ & 0.139 & 2.467 & $0.888-6.858$ & 0.083 \\
\hline \multirow[t]{2}{*}{ Site of tumor } & Lower-Middle thoracic & 86 & 1.000 & & & & & \\
\hline & Upper thoracic & 36 & 1.331 & $0.691-2.564$ & 0.392 & & & \\
\hline \multirow[t]{2}{*}{ Pathological depth of invasion } & $\mathrm{T} 1$ & 43 & 1.000 & & & 1.000 & & \\
\hline & $\mathrm{T} 2 / \mathrm{T} 3$ & 79 & 2.387 & $1.286-4.430$ & 0.006 & 2.706 & $1.437-5.094$ & 0.002 \\
\hline \multirow[t]{2}{*}{ Pathological lymph node status } & Negative & 62 & 1.000 & & & 1.000 & & \\
\hline & Positive & 60 & 1.885 & $1.111-3.196$ & 0.019 & 1.295 & $0.713-2.355$ & 0.396 \\
\hline \multirow[t]{2}{*}{ Lymphovascular invasion } & Negative & 38 & 1.000 & & & 1.000 & & \\
\hline & Positive & 84 & 2.182 & $1.131-4.210$ & 0.020 & 1.587 & $0.754-3.339$ & 0.224 \\
\hline \multirow[t]{2}{*}{ Postoperative AL } & No & 78 & 1.000 & & & 1.000 & & \\
\hline & Yes & 44 & 2.019 & $1.154-3.531$ & 0.014 & 2.078 & $1.209-3.572$ & 0.008 \\
\hline \multirow[t]{2}{*}{ Neoadjuvant chemotherapy } & No & 71 & 1.000 & & & & & \\
\hline & Yes & 51 & 1.041 & $0.612-1.771$ & 0.881 & & & \\
\hline
\end{tabular}

AL: Anastomotic leak; CI: confidence intervaI; HR: hazard ratio.

clinical data without identifying personal information was obtained before surgery from all patients. This study was approved by the Institutional Review Board of Yokohama City University.

\section{Results}

Patient characteristics. One-hundred and twenty-two patients underwent esophagectomy for esophageal cancer between 2008 and 2018. One-hundred and six patients were male, and 16 were female. The median age was 68 years (range $=40-82$ years). The median follow-up period was 72.5 months (range=13.9-125.2 months). Forty-four patients were categorized as having AL, and 78 were categorized as not having AL. Table II compares the patient characteristics between the two groups. Table II also shows the relationships between the occurrence of AL and the clinicopathological parameters. Lymph node dissection was significantly associated and tumor location marginally significantly associated with the incidence of $\mathrm{AL}$ ( $p=0.006$ and $p=0.097$, respectively).

Survival analyses. The respective OS rates at 1, 3 and 5 years after surgery were $71.1 \%, 43.9 \%$ and $40.2 \%$ in the AL group and $85.5 \%, 63.9 \%$ and $53.2 \%$ in the non-AL group, which were significantly different $(p=0.0049)$. The OS curves are shown in Figure 1. Univariate analyses showed that postoperative AL was a significant prognostic factor, as were the depth of tumor invasion, lymph node status and lymph vascular invasion for poorer OS (Table III). AL was selected for the final model to be analyzed by a multivariate analysis [hazard ratio $(\mathrm{HR})=2.078$, 95\% confidence interval $(\mathrm{CI})=1.209-3.572 ; p=0.008]$.
The respective RFS rates at 1, 3 and 5 years after surgery were $58.7 \%, 44.8 \%$ and $29.8 \%$ in the AL group and $68.4 \%$, $44.9 \%$ and $42.4 \%$ in the non-AL group, which were not significantly different ( $p=0.2306)$. The RFS curves are shown in Figure 2. Univariate analyses for the RFS showed that AL was a marginally significant prognostic factor (Table IV). However, AL was selected for the final model by a multivariate analysis $(\mathrm{HR}=1.805,95 \% \mathrm{CI}=1.081-3.014 ; p=0.024)$.

Recurrence pattern and causes of death. Regarding the sites of first relapse, there were no significant differences between the patients with and without AL (Table V). The cause of death was analyzed for all patients. The rates of esophageal cancer-related death and death due to other causes were similar between the patients with and without AL.

\section{Discussion}

The aim of the present study was to evaluate whether or not OS and RFS were shortened by the development of AL in patients who underwent curative resection for esophageal cancer. The major findings were that AL was observed in almost $35 \%$ of patients after esophageal cancer surgery and was an independent prognostic factor for poorer OS and RFS. To improve survival among patients with esophageal cancer, it is necessary to prevent their developing AL after surgery.

Firstly, we discuss the significant difference in the oncological outcomes between patients with and without 


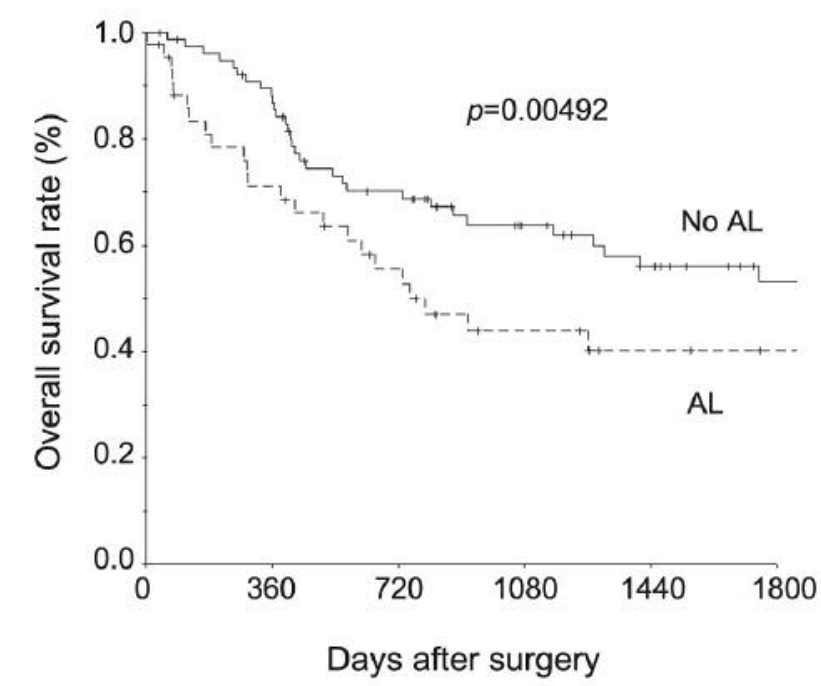

Figure 1. The overall survival curves of the patients with and without anastomotic leak $(A L)$. Five-year overall survival was $53.2 \%$ in the group without $A L$ and $40.2 \%$ in that with $A L$.

AL. A few reports have described the relationship between $\mathrm{AL}$ and survival in patients who underwent esophagectomy for esophageal cancer $(15,16)$. For example, Andreou et al. evaluated the clinical influence of $\mathrm{AL}$ in patients with gastric or esophageal cancer who underwent curative resection (17). Among 471 patients, 53\% were diagnosed with gastric cancer and $47 \%$ with esophageal cancer. In their study, AL was observed in $8.7 \%$ of patients $(5.3 \%$ gastric cancer and $12.9 \%$ esophageal cancer). The OS of the patients with $\mathrm{AL}$ was shorter than that of patients without $(\mathrm{HR}=2.29,95 \% \mathrm{CI}=1.43-3.69 ; p=0.001)$. The $\mathrm{OS}$ rate at 5 years after surgery was $39 \%$ in the AL group and $61 \%$ in the non-AL group. The RFS was also shorter in the patients with AL than in those without $(\mathrm{HR}=1.74,95 \% \mathrm{CI}=1.03$ $2.95 ; p=0.037)$. The RFS rate at 3 years after surgery was $35 \%$ in the AL group and 58\% in the non-AL group. Our results support the findings of these previous studies. Markar et al. evaluated the prognostic impact of AL in 2,944 patients with esophageal cancer who underwent esophagectomy at 30 university hospitals between 2000 and 2010 (18). In that study, among the 2,439 patients included in the final analysis, $208(8.5 \%)$ developed severe esophageal AL after surgery. The median OS after surgery was 35.8 months in the AL group and 54.8 months in the non-AL group $(p=0.002)$. The uni- and multivariate analyses showed that $\mathrm{AL}$ was a significant prognostic factor for OS (HR=1.28; 95\% CI=1.04-1.59; $p=0.022)$.

There are several possible explanations as to why postoperative AL affects the long-term outcome of patients with esophageal cancer. For example, the patients who developed AL after esophagectomy for esophageal cancer

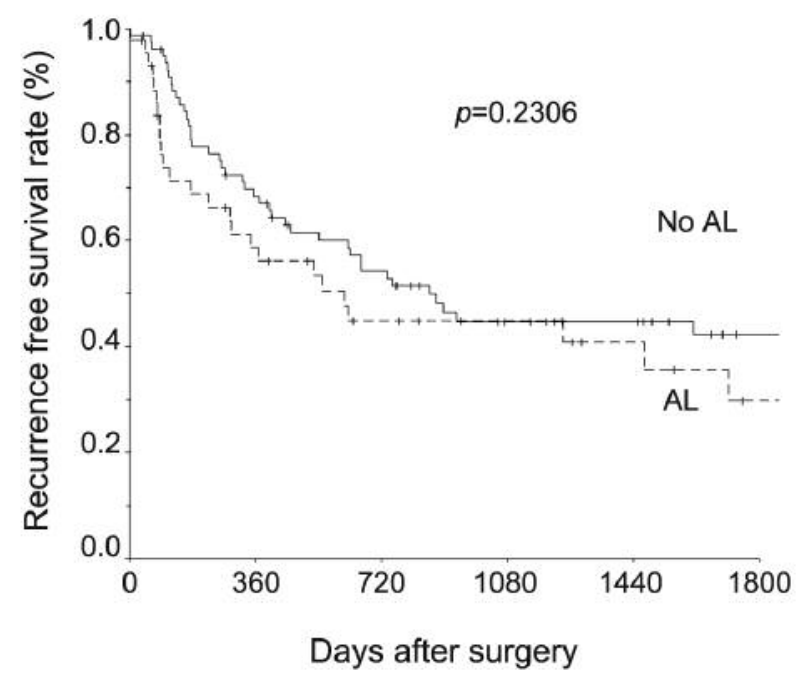

Figure 2. The recurrence-free survival curves of the patients with and without anastomotic leak $(A L)$. Five-year recurrence-free survival was $42.4 \%$ in the group without $A L$ and $29.8 \%$ in that with $A L$.

might have had some factors that led to reduced host immunity against residual tumor. However, the detailed mechanism underlying this is unclear at present (19-21).

In the present study, we defined postoperative AL based on the definition of leak adapted from the Surgical Infection Study Group, and the incidence of the AL was 36\%. However, the incidence of AL varies widely and has been reported to range from $0 \%$ to $53 \%$ (22). The main reason for this wide variation is the lack of an optimal definition of AL. For example, Markar et al. defined AL as a symptomatic disruption of the intrathoracic anastomosis classified as grade III or IV according to the Clavien-Dindo classification (18). Postoperative barium swallow was not routinely performed in their study. Andreou et al. also used the Clavien-Dindo classification, but a definitive definition of AL was not described. A postoperative radio contrast agent swallow examination was routinely performed at day 5 after surgery in their study (17). In addition, a recent systematic literature review of all articles dealing with anastomosis leak after esophagectomy only found 13 out of 33 publications that included a definition of AL (23). The clinical features used to define AL included evidence of hematoma or seroma at the neck wound, septicemia, peritonitis, peri-anastomosis collection, leak, local inflammation, evacuation of air or saliva, mediastinitis, abscess, empyema and pneumothorax. The majority of these studies reported the routine postoperative use of radiographic water-soluble contrast studies, but the timing of the contrast study ranged from 3 to 14 days after surgery.

Special attention is required when interpreting the current results, as there are some potential limitations associated 
Table IV. Univariate and multivariate Cox proportional hazards analysis of the relationship between clinicopathological factors and recurrencefree survival.

\begin{tabular}{|c|c|c|c|c|c|c|c|c|}
\hline \multirow[b]{2}{*}{ Characteristic } & & \multirow[b]{2}{*}{$\%$} & \multicolumn{3}{|c|}{ Univariate analysis } & \multicolumn{3}{|c|}{ Multivariate analysis } \\
\hline & & & HR & $95 \% \mathrm{CI}$ & $p$-Value & HR & $95 \% \mathrm{CI}$ & $p$-Value \\
\hline \multirow[t]{2}{*}{ Age } & $<68$ Years & 65 & 1.000 & & & & & \\
\hline & $\geq 68$ Years & 57 & 1.091 & $0.651-1.828$ & 0.742 & & & \\
\hline \multirow[t]{2}{*}{ Gender } & Female & 16 & 1.000 & & & 1.000 & & \\
\hline & Male & 106 & 1.590 & $0.683-3.702$ & 0.282 & 2.227 & $0.952-5.208$ & 0.065 \\
\hline \multirow[t]{2}{*}{ Site of tumor } & Lower-middle thoracic & 86 & 1.000 & & & & & \\
\hline & Upper thoracic & 36 & 1.032 & $0.737-1.447$ & 0.853 & & & \\
\hline \multirow[t]{2}{*}{ Pathological depth of invasion } & $\mathrm{T} 1$ & 43 & 1.000 & & & 1.000 & & \\
\hline & $\mathrm{T} 2 / \mathrm{T} 3$ & 79 & 4.623 & $2.265-9.434$ & $<0.001$ & 3.835 & $2.060-7.142$ & $<0.001$ \\
\hline \multirow[t]{2}{*}{ Pathological lymph node status } & Negative & 62 & 1.000 & & & 1.000 & & \\
\hline & Positive & 60 & 2.664 & $1.546-4.590$ & $<0.001$ & 1.475 & $0.841-2.587$ & 0.175 \\
\hline \multirow[t]{2}{*}{ Lymphovascular invasion } & Negative & 38 & 1.000 & & & 1.000 & & \\
\hline & Positive & 84 & 2.588 & $1.341-4.995$ & 0.005 & 1.623 & $0.831-3.168$ & 0.156 \\
\hline \multirow[t]{2}{*}{ Postoperative AL } & No & 78 & 1.000 & & & 1.000 & & \\
\hline & Yes & 44 & 1.393 & $0.845-2.298$ & 0.194 & 1.805 & $1.081-3.014$ & 0.024 \\
\hline \multirow[t]{2}{*}{ Neoadjuvant chemotherapy } & No & 71 & 1.000 & & & & & \\
\hline & Yes & 51 & 1.620 & $0.928-2.827$ & 0.089 & & & \\
\hline
\end{tabular}

AL: Anastomotic leak; CI: confidence intervaI; HR: hazard ratio.

Table V. Patterns of recurrence between the patients with postoperative anastomosis leakage $(A L)$ and those without.

\begin{tabular}{|c|c|c|c|c|c|}
\hline \multirow[b]{2}{*}{ Recurrence site } & & \multirow[b]{2}{*}{ All cases, n (\%) } & \multicolumn{2}{|c|}{ Postoperative AL, n (\%) } & \multirow[b]{2}{*}{$p$-Value } \\
\hline & & & No $(n=78)$ & Yes $(n=44)$ & \\
\hline \multirow[t]{2}{*}{ Lymph node } & Regional & $23(18.9)$ & $14(17.9)$ & $9(20.5)$ & 0.734 \\
\hline & Distant & $7(5.7)$ & $5(6.4)$ & $2(4.5)$ & 0.671 \\
\hline Local & & $12(9.8)$ & $10(12.8)$ & $2(4.5)$ & 0.195 \\
\hline \multirow[t]{4}{*}{ Distant site } & Lung & $12(9.8)$ & $8(10.3)$ & $4(9.1)$ & 0.977 \\
\hline & Liver & $11(9.0)$ & $6(7.7)$ & $5(11.4)$ & 0.290 \\
\hline & Bone & $5(4.1)$ & $2(2.6)$ & $3(6.8)$ & 0.255 \\
\hline & Other & $9(8.0)$ & $8(10.3)$ & $1(2.3)$ & 0.105 \\
\hline Disseminated & & $3(2.5)$ & $2(2.6)$ & $1(2.3)$ & 0.921 \\
\hline
\end{tabular}

Some patients had a first relapse at more than one site.

with this study. Firstly, this was a retrospective, singlecenter study with a small sample size. Our findings may therefore have been the result of chance in this series. Secondly, there may have been a selection bias in the present study. Generally, esophagectomy itself has a $30-40 \%$ morbidity rate and 1-2\% mortality rate. Surgeons thus avoid performing esophagectomy for certain patients, particularly elderly ones. The impact of AL may therefore have been artificially emphasized in this cohort. Thirdly, there was a time bias in this study, as the data were collected between 2008 and 2018. Surgical procedures and perioperative care might have changed over this period. Considering these limitations, the current results should be validated by another study.
In conclusion, the present study confirmed that the development of AL was a risk factor for poorer OS and RFS in patients who underwent esophagectomy for esophageal cancer. To improve survival of these patients, the development of AL after esophagectomy needs to be prevented.

\section{Availability of Data and Materials}

Data and materials are available to any researcher interested upon reasonable request to the corresponding author.

\section{Conflicts of Interest}

The Authors declare no competing interests in association with the present study. 


\section{Authors' Contributions}

Keisuke Kazama, Toru Aoyama and Ayaka Tamagawa made substantial contributions to conception and design. All Authors made substantial contributions to acquisition of data, or analysis and interpretation of data. Toru Aoyama, Keisuke Kazama, Yosuke Atsumi, Hiroshi Tamagawa, Ayaka Tamagawa, Keisuke Komor and Yasushi Rino were involved in drafting the article or revising it critically for important intellectual content. All Authors agreed to be accountable for all aspects of the work in ensuring that questions related to the accuracy or integrity of any part of the work are appropriately investigated and resolved. All Authors read and approved the final article.

\section{References}

1 Torre LA, Bray F, Siegel RL, Ferlay J, Lortet-Tieulent J and Jemal A: Global cancer statistics, 2012. CA Cancer J Clin 65: 87-108, 2015. PMID: 25651787. DOI: 10.3322/caac.21262

2 NCCN. NCCN Clinical Practice Guidelines in Oncology. Available at: https://www.nccn.org/professionals/physician_gls/ default.aspx

3 Lordick F, Mariette C, Haustermans K, Obermannová R and Arnold D: ESMO Guidelines Committee. Oesophageal Cancer: ESMO Clinical Practice Guidelines for diagnosis, treatment and follow-up. Ann Oncol 27: v50-v57, 2016. PMID: 27664261. DOI: $10.1093 /$ annonc/mdw329

4 Aoyama T, Murakawa M, Katayama Y, Yamaoku K, Kanazawa A, Higuchi A, Shiozawa M, Morimoto M, Yoshikawa T, Yamamoto N, Rino Y, Masuda M and Morinaga S: Impact of postoperative complications on survival and recurrence in pancreatic cancer. Anticancer Res 35: 2401-2409, 2015. PMID: 25862906.

5 Hayashi T, Yoshikawa T, Aoyama T, Hasegawa S, Yamada T, Tsuchida K, Fujikawa H, Sato T, Ogata T, Cho H, Oshima T, Rino Y and Masuda M: Impact of infectious complications on gastric cancer recurrence. Gastric Cancer 18: 368-374, 2015. PMID: 24634097. DOI: 10.1007/s10120-014-0361-3

6 Kano K, Aoyama T, Yoshikawa T, Maezawa Y, Nakajima T, Hayashi T, Yamada T,Sato T, Oshima T, Rino Y, Masuda M, Cho $\mathrm{H}$ and Ogata $\mathrm{T}$ : The negative survival impact of infectious complications after surgery is canceled out by the response of neoadjuvant chemotherapy in patients with esophageal cancer. Ann Surg Oncol 25: 2034-2043, 2018. PMID: 29748890. DOI: 10.1245/s10434-018-6504-8

7 Aoyama T, Oba K, Honda M, Sadahiro S, Hamada C, Mayanagi S, Kanda M, Maeda H, Kashiwabara K, Sakamoto J, Saji S and Yoshikawa T: Impact of postoperative complications on the colorectal cancer survival and recurrence: analyses of pooled individual patients' data from three large phase III randomized trials. Cancer Med 6: 1573-1580, 2017. PMID: 28639738. DOI: 10.1002/cam4.1126

8 den Dulk M, Marijnen CA, Collette L, Putter H, Påhlman L, Folkesson J, Bosset JF, Rödel C, Bujko K and van de Velde CJ: Multicentre analysis of oncological and survival outcomes following anastomosis leakage after rectal cancer surgery. Br J Surg 96: 1066-1075, 2009. PMID: 19672927. DOI: 10.1002/ bjs. 6694

9 Sierzega M, Kolodziejczyk P, Kulig J and Polish Gastric Cancer Study Group: Impact of anastomosis leakage on long-term survival after total gastrectomy for carcinoma of the stomach. Br J Surg 97: 1035-1042, 2010. PMID: 20632269. DOI: $10.1002 /$ bjs. 7038

10. Mirnezami A, Mirnezami R, Chandrakumaran K, Sasapu K, Sagar $\mathrm{P}$ and Finan P: Increased local recurrence and reduced survival from colorectal cancer following anastomosis leak: systematic review and meta-analysis. Ann Surg 253: 890-899, 2011. PMID: 21394013. DOI: 10.1097/SLA.0b013e3182128929

11 Lang H, Piso P, Stukenborg C, Raab R and Jähne J: Management and results of proximal anastomosis leaks in a series of 1114 total gastrectomies for gastric carcinoma. Eur J Surg Oncol 26: 168-171, 2000. PMID: 10744938. DOI: 10.1053/ejso.1999.0764

12 Sauvanet A, Mariette C, Thomas P, Lozac'h P, Segol P, Tiret E, Delpero JR, Collet D, Leborgne J, Pradère B, Bourgeon A and Triboulet JP: Mortality and morbidity after resection for adenocarcinoma of the gastroesophageal junction: Predictive factors. J Am Coll Surg 201: 253-262, 2005. PMID: 16038824. DOI: $10.1016 /$ j.jamcollsurg.2005.02.002

13 Sobin LH, Gospodarowicz MK and Wittekind C: International Union Against Cancer (UICC) TNM Classification of Malignant Tumors. Seventh Edition. New York: Wiley-Liss; 2010.

14 Peel AL and Taylor EW: Proposed definitions for the audit of postoperative infection: A discussion paper. Surgical Infection Study Group. Ann R Coll Surg Engl 73: 385-388, 1991. PMID: 1759770.

15 Junemann-Ramirez M, Awan MY, Khan ZM and Rahamim JS: Anastomosis leakage post-esophagogastrectomy for esophageal carcinoma: retrospective analysis of predictive factors, management and influence on long-term survival in a highvolume centre. Eur J Cardiothorac Surg 27: 3-7, 2005. PMID: 15621463. DOI: $10.1016 /$ j.ejcts.2004.09.018

16 Rutegård M, Lagergren P, Rouvelas I and Lagergren J: Intrathoracic anastomosis leakage and mortality after esophageal cancer resection: A population-based study. Ann Surg Oncol 19: 99-103, 2012. PMID: 21769467. DOI: 10.1245/s10434-011-1926-6

17 Andreou A, Biebl M, Dadras M, Struecker B, Sauer IM, ThussPatience PC, Chopra S, Fikatas P, Bahra M, Seehofer D, Pratschke $J$ and Schmidt SC: Anastomosis leak predicts diminished long-term survival after resection for gastric and esophageal cancer. Surgery 160: 191-203, 2016. PMID: 27067160. DOI: 10.1016/j.surg.2016.02.020

18 Markar S, Gronnier C, Duhamel A, Mabrut JY, Bail JP, Carrere $\mathrm{N}$, Lefevre JH, Brigand C, Vaillant JC, Adham M, Msika S, Demartines N, Nakadi IE, Meunier B, Collet D, Mariette C; FREGAT (French Eso-Gastric Tumors) working group, FRENCH (Fédération de Recherche EN CHirurgie), and AFC (Association Française de Chirurgie): The Impact of severe anastomosis leak on long-term survival and cancer recurrence after surgical resection for esophageal malignancy. Ann Surg 262: 972-980, 2015. PMID: 26469952. DOI: 10.1097/SLA. 0000000000001011

19 Dunn GP, Old LJ and Schreiber RD: The immunobiology of cancer immunosurveillance and immunoediting. Immunity 21 : 137-148, 2004. PMID: 15308095. DOI: 10.1016/j.immuni. 2004.07.017

20 Asaka S, Shimakawa T, Yamaguchi K, Katsube T, Usui T, Yokomizo H, Shiozawa S and Naritaka Y: Postoperative pneumonia after esophagectomy and systemic inflammatory response syndrome. Anticancer Res 39: 979-985, 2019. PMID: 30711984. DOI: 10.21873/anticanres.13202 
21 Goldfarb Y, Sorski L, Benish M, Levi B, Melamed R and BenEliyahu S: Improving postoperative immune status and resistance to cancer metastasis: A combined perioperative approach of immunostimulation and prevention of excessive surgical stress responses. Ann Surg 253: 798-810, 2011. PMID: 21475023. DOI: $10.1097 /$ SLA.0b013e318211d7b5

22 Blencowe NS, Strong S, McNair AG, Brookes ST, Crosby T, Griffin SM and Blazeby JM: Reporting of short-term clinical outcomes after esophagectomy: A systematic review. Ann Surg 255(4): 658-666, 2012. PMID: 22395090. DOI: 10.1097/ SLA.0b013e3182480a6a
23 Bruce J, Krukowski H, Al-Khairy G, Russell EM and Park GM: Systematic review of the definition and measurement of anastomosis leak after gastrointestinal surgery. $\mathrm{Br} \mathrm{J}$ Surg 88 : 1157-1168, 2001. PMID: 11531861. DOI: 10.1046/j.0007-1323. 2001.01829.x

Received November 15, 2019 Revised November 26, 2019 Accepted December 2, 2019 